\title{
Poetry and Drama: A Survey of Their Applicability to Language Teaching/Learning
}

\author{
Saeid Rahimipour \\ Department of Educational Sciences, Farhangian University, Ilam. Iran \\ *Corresponding Author E-mail: sdrahimipour@yahoo.com
}

Received: 21 September 2019, Revised: 06 December 2019, Accepted: 2 January 2020

\begin{abstract}
Recently, literature and its applicability as a powerful source of authentic and rich linguistic materials have received profound attention and consideration. Unlike the past, it is being searched and analyzed from any possible aspect for its efficiency and power of utilization in the class. This paper has tried to detect in the researches done on the applicability of literature to language teaching, specially the status of poetry and drama as two powerful genres of literature in the field of language teaching and learning as well as the detailed introduction of their feasibility and application to literature understanding and language teaching. The paper has tried to utilize them in their classes and devise ELT textbooks from theoretical viewpoint and pave the way for the practitioners and curriculum developers their mode of administration and deployment.
\end{abstract}

Keywords: Poetry, Drama, Literature, TEFL, Survey.

\section{Introduction}

Literature has always been a source of entertainment and intellectuality. Literary genres of different types have served their idiosyncratic purposes and fucnctions. Among the many literary genres the ones which lend themselves more to the process of language teaching and learning would be poetry and drama which are both roughly based on poetic lanauage. Generally, genre is attributed to the dominant class and style of literary practice. The term has been defined differently by many intellectuals and researchers. For example, (Widdowson, 2007) has defined genre as the application of language which is congruent with the certain schematic and textual conventions shared by all literary figures. In Bhatia's (1993) conception, genre has been defined as a distinguished communicative phenomenon represented by a set of communicative functions. Although the notion seems a little controversial, (Askehave and Swales, 2001), analyzing the genres found in different professional areas, account for the existing curricula of English language including literary genres (Paltridge, 1996; Bhatia, 1993). One possibility is that the genres are teachable as there are conventions for the rhetorical structures of different text types. Genres form the building blocks of literature as 
"literature has been interpreted differently for diverse purposes by the critics and the readers respectively" (Rahimipour, 2018). Literature genres have been recently deployed for educational purposes. Drama and poetry prove to be more alluring and attractive. They can be tailored towards the proficiency level of the learners easily. The application of literature genres, in general, calls for great theoretical justification and practical crystalization in classes. Short stories and novels have been given much academic consideration, but poetry and drama have roughley been touched upon approperiately. Alongside this shortage of academic consideration of the topic which, in a sense, adds to the novelty of the research, their application and consideration for applied purposes calls for more instantiation and implementation. This paper has tried to introduce the theoritical findings and practices on drama and poerty in order to provide the guidelines and instructions for their use in the classes. Hence, this research is an endeavor to detect the role of the selected genres of literature. It has tried to initiate the theoretical justification of literature for further use in the field of applied linguistics.

\section{Benefits of Using Poetry in TEFL}

As one of the major genres of English literature, poetry can pave the way for the learning and teaching of basic language skills. Metaphor serves the most prominent connection between learning and poetry. Because most poetry consciously or unconsciously makes use of metaphor as one of its primary methods, poetry offers a significant learning process.

Many learning benefits have been enumerated for studying poetry. The appreciation of the writer's composition process, which students gain by studying poems by components developing sensitivity for words and discoveries that may later grow into a deeper interest and greater analytical ability.

Many researchers have put forwarded different functions for poetry. (Saraç 2003) explains the educational benefits of poetry as follows:

a) Providing readers with a different viewpoint towards language use by going beyond the known usages and rules of grammar, syntax and vocabulary,

b) Triggering unmotivated readers owing to being so open to explorations and different interpretations,

c) Evoking feelings and thoughts in heart as well as mind,

d) Making students familiar with figures of speech (i.e. simile, metaphor, irony, personification, imagery, etc.) due to their being a part of daily language use.

Poetry has always been a big and joyful activity for man; its deployment for teaching in the class, for sure, would prove to be a novel experience. At this juncture, it can be stated that students become familiar with the supra-segmental aspects of the target language, such as stress, pitch, juncture, intonation by studying poetry which would give rise to the manifestation of other language skills too.

Through poetry, students can also study the semiotic elements in the target language.

Semiotic elements serve the purpose of cultural training as well. Hiller (1983:10) has stated that poems should be seen as hyper signs of which constituents, "semiotic signifiers", come together in their common relationship and lead to the "symbolic level" and this level is the one inclined to be signified in a poem. This notion can be described as follows: Signifier, Semiotic level, Signifier, PoemHypersign, Symbolic level signified.

Moreover, poetry employs language to evoke and exalt special qualities of life, and 
suffices readers with feelings. It is particularly lyric poetry which is based on feelings and provides still another emotional benefit. Poetry is one of the most effective and powerful transmitters of culture. Poems comprise so many cultural elements - allusions, vocabulary, idioms, and tone that are not easy to translate into another language (Sage, 1987).

Among the literary genres used in language teaching, poetry has proved to be of great feasibility in the class and for education because:

a) it is one of frequent appearance, b) due to their short length, they are perfectly suitable for a single classroom lesson, c) their peculiar structure; their characteristic linguistic features (unusual syntactic patterns, polysemy of words, alliteration, etc.) poems become favorite tools for language teachers, d) the evocative character of poetry, its imagery, its appeal to feelings and personal experience make it very interesting and enjoyable for the second language learner, e) poetry, especially can lead to a desirable creative expression in the foreign language and they usually provoke a strong response from the reader which will motivate further reading (Collie and Slater, 1987).

These ideas are consummated by Ramsaran's assertion that the importance of poetry and its usefulness in language classroom lies in the fact that poetry deviates from normal language in that it has some unusual ways of ordering words, or it attributes particular and imaginative meanings to words or combines sounds in a musical, non-ordinary way (phonological, lexical, syntactic, semantic, graph logical, and style (deviation 1983). Due to the nature of poetic language, it can be staged and tailored for different proficiency levels easily. Upon scrutiny, an applied linguists can plan the application of poems of different types in the classroom from the sheer phonetic puposes to the highest level of interpreting poetic language. The language teacher should exploit the deviancies of the poetic language in order to raise the language awareness of the learners towards the way in which language can be adapted or changed to fulfill different communicative purposes.

Example: Why the Waste Land?

The major factor in the insertion of materials in the course of teaching and learning through literature and mainly poetry genre is the question of the selection of the appropriate poems to serve the intended purpose and be of educational value. In this regard (McKay 1986) has asserted that "the key to success in using literature in ESL class seems to me to rest in the literary works that are selected". For example, The Waste Land offers great pedagogical opportunities for its magnificent language and language use, and its controversial underlying philosophy. This can be easily deployed by the practitioners in the classrooms for interpretation and analysis objectives. Its understanding proves to be demanding on the minds of the learners which is the unique property of this poem for discussion in the class and as an outside of the class activity. Sense, sound, semantics, culture, history, paragons, and many more features can be introduced via poems of this type which would be roughly out of question in any other way round. The following factors should be taken into account when we want to select a piece of poem for a special class.

\section{Content}

The major weakness of English language eductional textbook is that they are roughly culture free. They are solely based 
on the elements of education. The incorporation of the materials with the pragmatic features of the language is something which calls for drastic consideration linguistic elements. The area which is replete with such features as the make-up part of the language teaching and learning process, for sure, would be the insertion of peoms and poetic language. Events of different types give rise to the revelation of facts of different types providing inspiration for the creation of different works of art whose best reflection can be seen in poetry. The content or the starting point of the poetry is ignited by these events. Whenever it is revealed and composed, it is welcomed and appreciated by the readers and listeners. Moreover, it can have great educational objectives, too. From the point of view of a content analysis, the poem displays a series of features that make it very interesting for the students. First of all, the poem is one of the most relevant literary works of the last century. Both literally and culturally it marked a turning point. It challenged the established standards and brought about a new current named modernism that invaded all fields of cultural manifestations, not only in literature, but also in architecture or painting. This poem changed "the face of the twentieth century culture" (Selby, 1999). After the Great War, Europe, its fields, and its people were left exhausted.

The horrors of the war, the physical, emotional, political, and cultural devastation and chaos that it left behind inspired The Waste Land. T.S. Eliot, the author, like many of his contemporaries, convinced that the old cultural and social values, norms and beliefs had been blown apart by the war and the new experiences (Selby, 1999). These characteristics can not be conveyed to the learners by any other way but the analysis of the poem paves the way for enriching their power of thinking and understanding of the accompanying metalinguistic elements. They were no longer valid and a feeling of loss and of abandonment replaced them instead. Modernism can be compared to youth, because in this time of life, there are many new experiences going on. Learners may feel the poem is telling in some way their lives, the way they feel, their thoughts and feelings. They may identify with the poet and feel he is somehow telling their story of uneasiness in some moment of their lives; "it is important to select themes with which the students can identify" (McKay, 1986). Here rests the relevance and interest of The Waste Land; its reading both creates and demands a high degree of personal involvement from the learner. The poem allows for many interpretations, since it displays a series of mythical and symbolic parts which are for the reader to interpret basing on his own experience, on his "mental and emotional structures" (Traversi, 1976) ;therefore, we have the learners involved in their utmost imagination in the poem. If we devoid the learners of cultural, literary, social, and personal views of human being and the society of the country whose language is being learned, for sure, we would not be able to teach them in native like manner. This calls for the incorporation of literary genres like poetry more crucial in the fied of applied linguistics.

Despite its fictional character, The Waste Land is a good way to increase the cultural enrichment of the learners by providing them with an insight into the past (tradition) and modern culture of "the country whose language is being learnt" (Collie and Slater 1987). One of the most recurrent and relevant allusions of the poem is tradition; therefore, culture and past times play an important role in The Waste Land. 
The poem The Waste Land is, therefore, culturally and literarily relevant, in consonance with the learner's cultural background. It is motivating; it allows for personal involvement and cultural enrichment. Learners can draw from the poem and relate it to their personal experiences. They create their own poems as they interact with it, and this interaction implies involvement in the reading of the poem. Such a way of highlighting the reality of the usefulness of literature can, for sure, pave the way for the applicability of this genre to literature learning and language teaching.

\section{Form}

It is a long poem, whose organization is rather fragmentary. This allows the teacher to design activities and organize term classes at two levels. On the one hand, the individual fragments of the poem can be used for each single lesson, for example as divided by Eliot, or he may find an alternative fragmentation; on the other hand, the poem may be used for several sessions over one or two weeks. It has the advantage that it tells many different stories within the frame of a longer story, a kind of "super story", and this can be exploited by developing multiple exercises that deal with each sub-theme and with the general theme.

As Eliot acknowledges himself in the poem, it is "a heap of broken images", where voices and characters succeed one another and superpose. This novel organization and representation of experience is very motivating and will engage learners in genuine decoding of communicative meaning which manifest the deepest function of poetry.

Its unusual associations of words (collocations) or the peculiar meanings attributed to some words or expressions like "April is the cruelest month", "stirring dull roots with spring rain", "Winter kept us warm" etc. can be used by the teacher to have the learner reflect on the nature of the foreign language and on the different purposes that can be achieved by modifying the regular word order, altering the expected meaning of a word or inventing new combinations of two lexical items.

Another reason why we chose to work with The Waste Land is that it is a contemporary work and therefore, its language is modern and understandable. The combination of different languages (Latin, Italian, German, etc.) that appear in the poem is also very interesting and appealing for the learners. The teacher can make them reflect about the purpose of using those different languages and help them, to develop their knowledge of the rules of social use, together with the rules of grammar.

We are aware of the linguistic and conceptual difficulty of the poem. The fact that there are difficult areas, that the learners can overcome, is challenging and motivating and it is a further incentive to read and work on the poem. It is essential to make clear that experts show preference for authentic, non-simplified texts, since they are much more valuable from the linguistic point of view and also because they provide real language in context and natural stimuli, by the exploration and discussion of content, that lead to examination of language (Brumfit and Carter, 1986). (Grellet 1981) claims that the "difficulty is not on the text itself but on the exercises that are required of the students. This may make the procedure a little demanding on the part of the teacher for the selection of the appropriate poem and demanding on the part of the learners for understanding and joy". 
Literature can improve reading comprehension to a great extent, because reading proficiency rests on the interaction between reader and writer, interaction mediated by the text (McKay, 1986). The more motivating and enjoyable the text, the more intense, real and powerful the interaction will be (Brumfit and Carter, 1986). When reading The Waste Land, learners are communicating, deciphering meanings and reflecting on language and communication strategies in the foreign language as they are "crucial factor[s] in the development of language learning abilities" (Brumfit and Carter 1986). Cassany (1999) goes a bit further and claims that reading aids develop writing abilities by spurring their own imaginative writing and by providing them with examples of language use.

\section{Proposal of Activities to be Implemented with the Waste Land}

These activities are thought to be some guiding outline to the work with The Waste Land as a language teaching resource. They are addressed to intermediateadvanced learners of English at university level. Following (Maley 1996), we will divide our exercises into four main sections: responding, analyzing, writing, and experiment further.

These are what traditionally have been called pre-reading activities:

1. Think with a partner of a situation where you felt sad, or even desolated. This may give rise to a myriad of responses, for example when someone in the family died, or when failing in an exam.

2. Deducing from the title. What do you think the poem is about? Work in pairs. Here we may expect answers such as: a war, an epidemic that killed many in a small region, destruction of fields or crops by the enemy, abandonment of the family, poverty due to lack of rain and dried crop.
3. Think of things that may "waste" a land, or a person. Brainstorming with the whole class, the teacher writes down on the blackboard. Students may come up with words such as abuse, floods, draught, hard work, stress, tension, and so on.

4. With your partner, think of a general context out of which such a poem could have come to be: country, epoch, personal situation of the poet, economic and political happenings, etc. For example, learners may think of a family in the middle ages, whose fields have been devastated by a flood and who are starving. The whole county, for example England, is suffering from an epidemic due to the floods, and the poet, the son of the poor family decides to write his story.

With these initiating activities, the teacher soothes the path of the reading exercise and guides the learners to what they will be dealing with the following days. It is important that the learners predict what will come and that they have some previous idea of what they are going to read. This is a very important strategy not only in language learning, but also in communication (Maingay, 1983).

5. Read the poem at home.

Analysis: the activities in this section lead to a deeper analysis of the poem both as content and form are concerned: local and global vision.

6 . What is the poem about? Where is it set? What is the central theme of each of the five parts of the poem? Here the teacher should provide the learners with some kind of background information about the general epoch of the poem and the events that were taking place in Europe at that time. Providing background information to the learners is a very good help to improve their understanding of the text, and thus, enhance the pedagogical effect of the activities carried out (Lazar, 1993). There exist several ways of presenting this 
information, as a mini lecture, as a reading or listening comprehension or as a research project for students to implement (Lazar, 1993: 38).

7. The poem The Waste Land has the peculiarity, as you have observed, of being "split up" into many different structural fragments. With a partner identify those different fragments and think of an adjective or expression that best defines that particular fragment. The fragments they may identify can be the burial of the death, the maimed Fisher King, the slow, sad passing of the seasons and the coming of the cold winter, etc. The words or expressions used to describe these fragments can be death, desolation, sadness, loneliness, and coldness.

8. The following procedures can be deployed as follows;

a) All the class, think of some expressions or adjectives that define the feelings that the poem provokes in you,

b) War, fragmentation, death, desolation, sadness, destruction, loneliness are some of the feelings the poem attempts to arise in the reader. Find with your partner the passages, metaphors or allusions in the poem that mostly provoke those feelings in you, or the passages the poet intended to provoke you those mentioned feelings,

c) Try to find, with the use of a dictionary, the opposites of the words you used to define the feelings you got when reading The Waste Land.

With these exercises, we use the recurrent fragmentation of the poem and the repeated allusions to death and desolation to develop the lexical competence of our students. Vocabulary exercises are based on feelings of sadness and loneliness which will, no doubt, make the learner interact in the classroom and in the group.

9. More detailed strategies can be deployed as presented: a) Look carefully at the first part of The Waste Land, "The burial of the death" and try to delimit the main themes. Work in pairs. They may pinpoint as recurrent themes of the first part the following: fear of death, but recognition of its presence in modern life, life under the earth, hope for the future, tradition, spiritual desolation, love.

b) Find the themes you have just talked about in the remaining sections of the poem and try to see where they find their unity. Learners may find Tiresias as the one who unites the poem; every theme boils down to this mythological character.

This exercise is aimed to direct students towards a further understanding of the poem.

10. Round all regular verbs that you find and underline irregular ones. Establish the tense they are in (simple past, present perfect, conditional, etc.) and try to determine their function. Do the same with the modal verbs you encounter in your reading. This is grammar practice.

11. We have already talked about the fragmentary structure of the poem; there we can see different forms of telling a story: description, narration, dialogue; try to identify them in The Waste Land. Can you also think of a communicative purpose for the use of each of them in the concrete situation?

12. As you have observed, in the poem there are several dialogues. With a partner work out to transform these into "habitual", colloquial, today English.

13. Practice reading aloud some stanzas of the poem in small groups. What do you notice about the rhythm, speed, intonation?

14. Think with a partner of things that make you feel sad and that make you frightened.

Write them down in a list and write simple sentences with those words or 
expressions. Learners may write down things such as war, poverty, violence, abuse, or loneliness.

15. Write a short poem, only 10 lines, where you express you fears and sadness. Use the sentences and the words listed with your partner. Work alone.

16. Choose ten words from the poem that have to do with hope for the future and use them to write a short text with them with the title Hope for the future.

17. a) What do you think the author looked like? With a partner list a series of characteristics you think he may have had, both physically, you may even draw him, and mentally. Think of where he may have been born, what his occupation might have been, apart from writing poetry, or whether he had a family.

b) Then, invent and write a biography for the author. The list of activities that could be included in this section will be too much.

The experimenting further section, can be carried out by implementing a comparison of the poem of T.S. Eliot, with some previous and some posterior poems to see the differences at the thematic (symbols, conventions, topics) and structural levels.

The implementation of these activities can extend over one class period, but as we have already said above, this intends to be an outline of suggestions to use the poem The Waste Land as a resource for the teaching of English within the principles of the communicative approach. These lay importance on the development of social competence and show our students how to communicate in real life situations in the foreign culture and in the foreign language. The teacher has the responsibility of guiding her students to "learn to learn". This refers to the capacity of students to develop their own learning, their autonomy as language learners and the power of poetry in brainstorming the learners' mind.

These are not literature specific since these features also appear in ordinary language use and also in nursery rhymes, proverbs or publicity slogans, just to cite a few examples; however, in literature these show a higher incidence. We talk therefore, of a literary use of language.

\section{Benefits of Using Drama to Language Teaching}

Dramatic language and genre has proved to outperform other literary genres in case of language learning and teaching. Its poetic nature and prose, its collequial and formal styles, its demonstration on the stage, and many more points all add to and assign priority of this genres over the other in the fiedl of applied linguistics. Using drama in a language classroom is a good resource for language teaching. It is through the use of drama that learners become familiar with grammatical structures in contexts and also learn about how to use the language to express, control, and inform. The use of drama raises the students' awareness towards the target language and culture. In this context, the use of drama as a tool rather than an end gains importance in teaching a foreign language. Yet, there is one obvious danger: cultural imposition should be severely avoided since it results in the loss of language ego and native language identity in many cases. To put it differently, language learning should be accompanied by cultural elements but not entirely culture-biased. For this reason, the new language and the context of the drama should fuse into a language learning process with high interest, relevance and enjoyment. Learners should make use of drama to promote their comprehension of life experiences, reflect on particular circumstances and make sense of their 
extra linguistic world in a deeper way (Sarıçoban, 2004). The educational benefits of drama, according to (Lenore, 1993), are as follows:

a) Stimulates the imagination and promotes creative thinking,

b) Develops critical thinking skills,

c) Promotes language development,

d) Heightens effective listening skills,

e) Strengthens comprehension and learning retention by involving the senses as an integral part of the learning process, f) Increases empathy and awareness of others,

g) Fosters peer respect and group cooperation,

h) Reinforces positive self-concept,

i) Provides teachers with a fresh perspective on teaching.

Some other educational benefits of using drama in a foreign language class can be listed as follows (Mengü, 2002):

a) Bringing authenticity into the classroom,

b) Exposing the learners to the target culture as well as the social problems a society may be undergoing,

c) Increasing creativity, originality, sensitivity, fluency, flexibility, emotional. stability, cooperation, and examination of moral attitudes, while developing.

communication skills and appreciation of literature.

d) Helping learners improve their level of competence with respect to their receptive and productive skills,

e) Providing a solid basis for the learners to bridge the gap between their receptive and productive skills,

f) Offering students the space and time to develop new ideas and insights in a range of contexts,

g) Enabling students to develop new understandings and forms of knowing not accessible in other more traditional ways of learning.
In other words, the use of drama seems to be an effective technique in today's communication-based, student-centered foreign language teaching. Since it is an authentic material, it helps students to promote their comprehension of the verbal / nonverbal aspects of the target language they are trying to master. Particularly, teachers, who wish to make language learning more colorful, motivating and interesting, can make use of drama in their language classes. Since drama is the reenactments of social events, students improve their personality and code of behavior. What many modern and postmodern language teaching methods are trying to convey can be directly and indirectly manifested and christalized in stage and style of drama. Thus, they can achieve more meaningful and realistic teaching from which students can benefit to a great extent. The more we theoretically justify the elements, the more they lend themselves to better deployment in the classes.

\section{Drama}

Needless to say, literature-based dramatic activities are valuable for ESL/EFL. They facilitate and accelerate development of the oral skills since they motivate students to achieve a clearer comprehension of a work's plot and a deeper comprehension and awareness of its characters. Though drama in the classroom can assume many forms, there are three main types, which are dramatization, role-playing, and improvisation.

\section{Dramatization}

Dramatization requires classroom performance of scripted materials. Students can make up their own scripts for short stories or sections of novels, adapting them as closely as possible to the real text. Drama lends itself to different

$80 \mid$ Page 
modification. For example, in Waiting for Godot "language dissolves more and more as we go on in the play and the dialogue between the characters turns into monologue" (Rahimipour, 2011) which can be used as a teaching technique. Based on the story, they must guess what the characters would say and how they would say it. Scripts written by students are also probable with plays. Poems comprising one or more personae may also be scripted by students. Students should attentively read assigned sections of dialog in advance and be able to answer questions about characters and plot. They should indicate vocabulary, idioms, or dialog they don't understand and words them cannot pronounce. Students next rehearse the scene with their partners. Although they don't memorize it, they learn it well enough to make eye contact and say their lines with meaning and feeling. Moreover, they discuss semiotic aspects of staging the scene (i.e. facial expressions, gestures, and the physical aspects). Dramatic themes and texts can be deployed authentically. One can see for example that “O'Neill has tried to look at the susceptible layer of the society and human obsessions through his drama. For this he intermingled past, present, and novel techniques to be as impressive as possible" (Rahimipour, 2019) which may add to the richness of dramatic materials. At last, the dramatization is presented before the class.

\section{Improvisation and Role-Playing}

Both improvisation and role-playing may be developed around the characters, plot, and themes of a literary work. Improvisation is a more systematic activity, i.e., dramatization without a script. There is an identifiable plot with a beginning, middle, and end in improvisation. However, in role playing, students picture characters from the work being read and join in a speaking activity other than a dramatization, such as an interview or panel discussion.

\section{Group Activities}

Making each student responsible for facts and ideas to be contributed and discussed, group activities stimulates total participation. All students are involved and the participation is multidirectional. When teaching English through literature, some of the group activities used in language classroom are general class discussion, small-group work, panel discussions, and debates. All of these group activities both develop the speaking abilities of the students and give importance to pronunciation practice. Teachers indicate pronunciation errors of the students during the act of such activities so as to correct such errors (Stern, 1991). Literary works have proved to lend themselves to group activities due to their alluring and rigorous characteristics.

\section{Birthday Party}

One of the frequently used English plays in the classes for the purpose of lanuage teaching and learning has been Birthday party by Harold Pinter. He is an illustrious English playwright who has tried to project upon the minds of post modern man the dominant existential obsessions of postmodern man in his drama. His dramatic comedy of menace highlights the social, individual, and political features of different types which have proved to be the top problems of the majority of the societies. The insertion of this play in the classes on the line of language learning and teaching can assign on the learners information of different types whose provision would be out of questions via any other educational materials. The charaters of the play like Stanley, Mccane, 
Goldberg, and Lulu can exemplify many of the common people and figures of postmodern societies. This atmosphere dominating the play creates umost authenticity of materials, modes of presentation, and schools of thoughts for the learners to learn language and the real features of the county in which that language is being learned. The process of learning and teaching would be more real life and simulated for the learners and pave the bed for language learning as well as culture learning too. This special power of drama in case of implementation in the classes in the realm of applied linguistics proves to highly significant and crucial for utilization purposes.

\section{Conclusion}

With the advent of communicative approaches, the application of literature and literary genres to language teaching and learning has received profound attention and consideration among applied linguistics. Search in the efficiency of the genres with special proficiency level, subjects, and settings have a hot place in the field of language learning and language testing. This paper provided directly what theoretically other researchers have come up with regarding the application of drama and poetry in applied linguistics. It revealed the illustration of poetry and drama as two powerful genres of literature in TEFL and highlighted theoretically their feasibility and the ease of implementation and administration in the classes by practitioners and curriculum developers to pave the way for their widespread use and applicability in the classes. For sure, the theoretical justification and the guidelines for their development in the class would enhance their practicality and feasibility by practitioners and learners respectively.

\section{References}

Askehave, I, Swales, JM. (2001). Genre Identification and Communicative Purpose: A Problem and a Possible Solution, Applied Linguistics, 22:195-212.

Bhatia, VK. (1993). Analyzing Genre: Language Use in Professional Settings. London: Longman Group UK Limited.

Brumfit, J, Carter RA. (1986): Literature and Language Teaching, Oxford: Oxford University Press.

Cassandy, D. (1999). Construir la escritura, Barcelona: Paidós Comunicación.

Collie, J, Slater, S. (1987). Literature in the Language Classroom, Cambridge, UK: Cambridge University Press.

Grellet, F. (1981). Developing Reading Skills, Cambridge: Cambridge University Press.

Hiller, JP. (1983). Teaching Poetry in the Foreign Language Classroom: Theory and Practice, PhD Dissertation, State University of New York: New York.

Lazar, G. (1993). Literature and language teaching: a guide for teachers and trainers, Cambridge: Cambridge University Press.

Lenore, K.L. 1993. The Creative Classroom. A Guide for Using Creative Drama in Classroom, U.S.A.: Elsevier, Inc.

Maley, A. (1989). Down from the Pedestal: Literature as Resource in Literature and the Learner: Methodological Approaches, Cambridge: Modern English Publications.

Maingay, S. (1983). Making Sense of Reading, Hong Kong: Nelson Harrap.

Mckay, S. (1986). Literature in the ESL Classroom, In C.J. Brumfit and R.A. Carter (Eds.), Literature and Language Teaching , Oxford: Oxford University Press, 191-198. 
Mengü, HI. (2002). A Suggested Syllabus for the Drama Teaching Course in ELT Departments, M.A thesis in Linguistics, Hacettepe University, Ankara.

Paltridge, B. (1996). Genre, text type, and the language learning classroom, ELT Journal, 50:237-243.

Rahimipoor, S. (2011). Henrik Edoyan, Hashem, Masoud. Self-revelation in Samuel Beckett's language, Procedia - Social and Behavioral Sciences, 28:820-824.

Rahimipour, S. (2018). Comparative Survey of Colonialism in Achebe and Pinter's Works, The Journal of Applied Linguistics and Applied Literature: Dynamics and Advances, 6:163-177.

Rahimipour, S. (2019). The Detection of Morality Crisis in Eugene 0'Neil's the Rope, Journal of English Literature and Cultural Studies, 2:42-48.

Ramsaran, S. (1983). Poetry in the language classroom. ELT Journal, 37:36-43

How to cite this article: Saeid Rahimipour, Poetry and Drama: A Survey of Their Applicability to Language Teaching/Learning. International Journal of Advanced Studies in Humanities and Social Science, 2020, 9(1), 72-83.
Sage, H. (1987). Incorporating Literature in ESL Instruction, New Jersey: Prentice-Hall, Inc.

Saraç, S. (2003). A Suggested Syllabus for the Teaching of Poetry Course in ELT Departments of Turkey, M.A thesis in Linguistics, Hacettepe University, Ankara.

Sarıçoban, A. (2004). Using Drama in Teaching Turkish as a Foreign Language. Eurasian Journal of Educational Research, 14:13-32.

Selby, N. (Ed.). (1999). T. S. Eliot the Waste Land. A Reader's Guide to Essential Criticism. New York: Palgrave Macmillan. Stern, HH. (1983). Fundamental Concepts of Language Teaching. London: Oxford University Press.

Widdowson, HG. (2007). Discourse Analysis. Oxford: Oxford University Press. http://www.ijashss.com/article 105619.html 